Journal of Case Reports 2020;10(4):269-270

\title{
Critical Mitral Stenosis: A Blessing in Disguise
}

\author{
Santosh Kumar Sinha, Mukesh Jitendra Jha, Puneet Aggarwal, Vikas Mishra \\ Department of Cardiology, LPS Institute of Cardiology, GSVM Medical College, Kanpur, UP, India.
}

\section{Corresponding Author:}

Dr Santosh Kumar Sinha

Email: fionasan@rediffmail.com

This is an Open Access article distributed under the terms of the Creative Commons Attribution License (creativecommons.org/ licenses/by/3.0).

Received : May 1,2020

Accepted : August 21,2020

Published : December 30, 2020

\begin{abstract}
Background: Mitral stenosis (MS), accounts for $25 \%$ of rheumatic heart disease. Systemic arterial embolization is serious, sometimes fatal, complication of MS. Around $20 \%$ of patients with rheumatic MS may encounter systemic embolism during course of disease. Case Report: A 24-year-old male with worsening dyspnea was diagnosed with moderate MS with mitral valve area (MVA) of $1.4 \mathrm{~cm}^{2}$ and atrial fibrillation (AF) six years back. He was advised warfarin to maintain INR between 2 to 3 . He had visited outdoor department 2 months back after a lost to follow up. His INR was 1.2 suggesting inadequate warfarinization. His MS had progressed as echocardiogram revealed critical MS (MVA $=0.5 \mathrm{~cm}^{2}$ ). There was huge mobile, ping-pong thrombus inside left atrium which failed to embolize because of critical MS which turned out to be blessing in disguise for him. He was advised open mitral valvotomy. Conclusion: Effective anticoagulation is very important for patients with MS having AF.
\end{abstract}

Keywords: Anticoagulants, Atrial Fibrillation; Embolism, Mitral Valve Stenosis, Rheumatic Heart Disease.
According World Health Organization (WHO) in 2015, rheumatic heart disease (RHD) accounted for $0.43 \%$ of global disability-adjusted life-years due to any cause [1]. Mitral stenosis (MS), a curable morbid valvular condition, accounts for $25 \%$ of RHD cases. Atrial fibrillation (AF) is frequent in patients with rheumatic MS. Pressure overload leads to marked structural and electrical remodelling of left atrium. The frequency of persistent AF increases with age and paroxysmal, asymptomatic, AF seems even more frequent. Oral anticoagulant therapy is mandatory when AF complicates MS, regardless of its severity and CHA2DS2-VASc score. Systemic arterial embolization is a serious, sometimes fatal, complication of MS. Around $20 \%$ of patients with rheumatic MS have a chance of suffering a systemic embolism during the course of the disease and that recurrent emboli occur in 50\% of those patients with a history of a prior embolism. Patients without embolism are reasonably protected with an intensity of anticoagulation for an INR of 2.0-3.0.
A 24-year-old male presented with exertional dyspnea, and palpitation - New York Heart Association (NYHA) class II for past six years progressing to class III for past six months. Transrthoracic echocardiogram six year back revealed moderate mitral stenosis (MS) with mitral valve area (MVA) of $1.4 \mathrm{~cm}^{2}$, mean gradient across mitral valve: $8 \mathrm{mmHg}$ and Wilkin's score: 8/16 (M2C2T2S2). As patient had atrial fibrillation (AF), he was advised warfarin $2 \mathrm{mg}$, metoprolol $50 \mathrm{mg}$, frusemide $40 \mathrm{mg}$, and erythromycin prophylaxis for rheumatic fever. He had visited outdoor department 2 months back after a lost follow up. His MS had progressed as he had developed secondary pulmonary hypertension with variable, grade IV long diastolic rumbling murmur. His international normalized ratio (INR) was 1.2 which was suggestive of inadequate warfarinization. Repeat echocardiogram revealed critical MS with MVA of $0.5 \mathrm{~cm}^{2}$, mean gradient $28 \mathrm{mmHg}$ and Wilkin's score: 10/16 (M3C2T3S2) [Fig.1]. There 


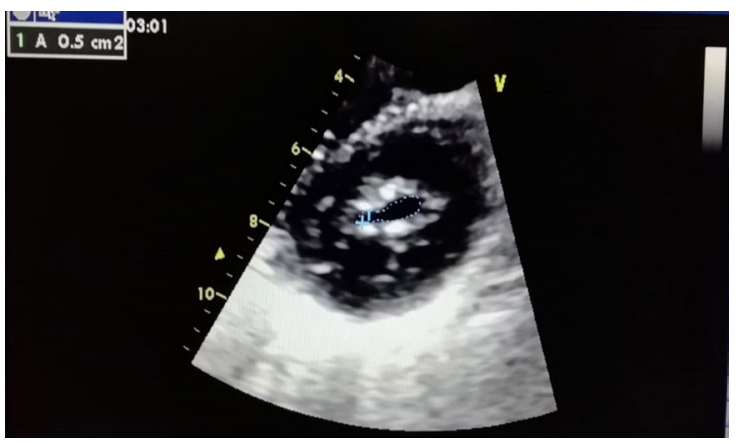

Fig.1: Echocardiogram revealed critical MS with MVA of $0.5 \mathrm{~cm}^{2}$.

was a huge mobile, ping-pong thrombus inside left atrium which failed to embolize because of critical MS which turned out to be a blessing in disguise for him [Fig.2,3]. In lieu of above finding, he was referred for open mitral valvotomy which was successfully done.

Effective anticoagulation is very important for patients with MS having AF. Our patient had suffered treatment failure as he was lost to follow up, had possible food or drug reaction causing fall of his INR below therapeutic range. These patients should be educated about follow up, stringent anticoagulation and possibility of adverse food or drugs reactions with warfarin.

Contributors: SKS: Drafting the work and patient management; MJJ: substantial contributions to the conception and critical review of the work. PA and VM: critical inputs into the manuscript. SKS will act as a study guarantor. All authors approved the final version of the manuscript and are responsible for all aspects of the study.

Funding: None; Competing interests: None stated.

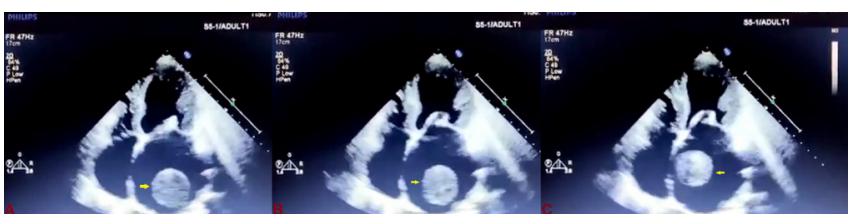

Fig.2: Huge mobile, ping-pong thrombus (yellow arrow) inside left atrium which moved near the tip of mitral valve.

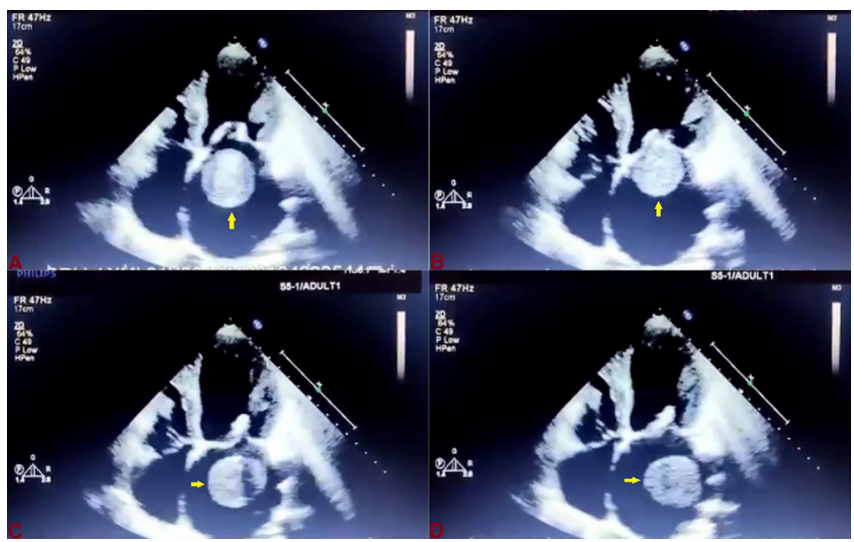

Fig.3: Huge mobile, ping-pong thrombus (yellow arrow) inside left atrium which moved near the tip of mitral valve but was stopped getting dislodged because of critical mitral stenosis.

\section{References}

1. Watkins DA, Johnson CO, Colquhoun SM, Karthikeyan G, Beaton A, Bukhman G, et al. Global, regional, and national burden of rheumatic heart disease, 1990-2015. N Engl J Med. 2017;377:713-722.

2. Nishimura RA, Bonow RO, Erwin JP, Ruiz CE, Sorajja P, Thomas JD. AHA/ACC valvular heart disease guideline Circulation. 2014:129. 